Chapman University

Chapman University Digital Commons

Food Science Faculty Articles and Research

Science and Technology Faculty Articles and

Research

$1-31-2018$

Lowering Greening of Cookies Made from Sunflower Butter Using Acidic Ingredients and Effect on Reducing Capacity, Tryptophan and Protein Oxidation

Sihui Liang

Hanh Lan Tran

Lilian Were

Follow this and additional works at: https://digitalcommons.chapman.edu/food_science_articles

Part of the Botany Commons, Food Chemistry Commons, and the Other Plant Sciences Commons 


\section{Lowering Greening of Cookies Made from Sunflower Butter Using Acidic Ingredients and Effect on Reducing Capacity, Tryptophan and Protein Oxidation}

Comments

NOTICE: this is the author's version of a work that was accepted for publication in Food Chemistry. Changes resulting from the publishing process, such as peer review, editing, corrections, structural formatting, and other quality control mechanisms may not be reflected in this document. Changes may have been made to this work since it was submitted for publication. A definitive version was subsequently published in Food Chemistry in 2018. DOI:10.1016/j.foodchem.2018.01.118

The Creative Commons license below applies only to this version of the article.

\section{Creative Commons License}

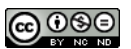

This work is licensed under a Creative Commons Attribution-Noncommercial-No Derivative Works 4.0 License.

\section{Copyright}

Elsevier 


\section{Accepted Manuscript}

Lowering greening of cookies made from sunflower butter using acidic ingredients and effect on reducing capacity, tryptophan and protein oxidation

Sihui Liang, Hanh Lan Tran, Lilian Were

PII: S0308-8146(18)30133-X

DOI: https://doi.org/10.1016/j.foodchem.2018.01.118

Reference: FOCH 22307

To appear in:

$$
\text { Food Chemistry }
$$

Received Date: $\quad 8$ August 2017

Revised Date: $\quad 12$ December 2017

Accepted Date: $\quad 17$ January 2018

Please cite this article as: Liang, S., Tran, H.L., Were, L., Lowering greening of cookies made from sunflower butter using acidic ingredients and effect on reducing capacity, tryptophan and protein oxidation, Food Chemistry (2018), doi: https://doi.org/10.1016/j.foodchem.2018.01.118

This is a PDF file of an unedited manuscript that has been accepted for publication. As a service to our customers we are providing this early version of the manuscript. The manuscript will undergo copyediting, typesetting, and review of the resulting proof before it is published in its final form. Please note that during the production process errors may be discovered which could affect the content, and all legal disclaimers that apply to the journal pertain. 
Lowering greening of cookies made from sunflower butter using acidic ingredients and effect on reducing capacity, tryptophan and protein oxidation

Sihui Liang ${ }^{1}$, Hanh Lan Tran ${ }^{2}$, Lilian Were ${ }^{1}$

${ }^{1}$ Food Science Program, Schmid College of Science and Technology, Chapman University, One University Drive, Orange CA 92886, USA

${ }^{2}$ Food Science and Technology, Nong Lam University, Ho Chi Minh city, Viet Nam

*Contact information for Corresponding Author

Lilian Were, Ph.D.

Chapman University

Ph: 714-744-7895

Fax: 714-289-2041

E-mail: were@chapman.edu 


\begin{abstract}
Lowering of greening formed from oxidized chlorogenic acid (CGA) and amino groups, and favoured at alkaline $\mathrm{pH}$, was investigated using acidic ingredients (sour cream, buttermilk, yoghurt, and honey) in sunflower butter cookies. Cookies with maple syrup added were used as a positive control. Changes in greening intensity, greening reactants (total phenols, CGA, protein), antioxidant capacity, tryptophan and Schiff base fluorescence were measured. Percentage greening, $\mathrm{pH}$ and $\mathrm{a}_{\mathrm{w}}$ of cookies followed the same order: maple syrup $>$ sour cream $\geq$ buttermilk $>$ yoghurt> honey. $\mathrm{pH}$ was positively correlated with greening intensity $(\mathrm{r}=0.77)$ and negatively correlated with CGA (r=-0.96). Total phenolic content, antioxidant capacity, tryptophan and Schiff bases were similar among cookies. The results suggest it is possible to decrease greening by minimizing storage time and using acidic ingredients. Minimal greening with acidic ingredients can extend the application of sunflower butter as a baking ingredient without loss of free radical-scavenging capacity, or higher protein oxidation.
\end{abstract}

Keywords: acidic ingredients; chlorogenic acid; greening, $\mathrm{pH}$; sunflower butter, water activity 


\section{Introduction}

Legume and nut butters and spreads are a good source of plant based protein and fat. However, allergies are a concern that both manufacturers and consumers must contend with. Peanuts are the major cause of food related anaphylactic shock, while tree nuts are also a major source of allergies in many western countries (Sicherer, Munoz-Furlong, Godbold, \& Sampson, 2010). Sunflower seed spread, and butter, is not a major source of allergies compared to legume or nut butters and spreads (Hsu \& Katelaris, 2007). Sunflower butter can thus be consumed by the estimated $1 \%$ of those allergic to peanuts and tree nuts in the U.S population (Sicherer et al., 2010). Unlike milk, egg, and wheat allergies which children can outgrow, allergies to peanut and tree nuts can be lifelong (Boyce et al., 2011). An allergy to one food does not translate to an allergy for other foods (Sicherer et al., 2010). For adults not allergic to dairy (Nwaru et al., 2014), but who are allergic to peanut and tree nuts without co-allergies to sunflower seeds, use of sunflower butter is an alternative in baking applications. Sunflower seeds used to make butter and spreads contain up to $20 \%$ crude protein (Dorrell \& Vick, 1997) in addition to a high antioxidant potential due to the high chlorogenic acid (CGA) content (Weisz, Kammerer, \& Carle, 2009), making sunflower butter a source of both protein and phenols.

Greening in baked products with sunflower butter is attributed to the high CGA content in sunflower seeds compared to other plant based butters. This high CGA content results in green to blue pigment formation when CGA dimerizes with itself under alkaline conditions. The CGA dimer then oxidizes to form highly reactive $o$-quinones which can subsequently react with amino acids in an aqueous, alkaline environment to form green trihydroxy benzacridine (TBA) derivatives (Liang \& Were, 2018a, 2018b). The rate of greening increases with $\mathrm{pH}$ and heat, which can limit the application of sunflower butter in bakery applications (Wildermuth, Young, 
\& Were, 2016). Lowering greening is thus paramount if sunflower butter is to be commercialized or adopted by consumers for baking applications where greening is unwanted.

Use of maple syrup, a higher $\mathrm{pH}$ sweetener in baking encourages greening (Liang \& Were, 2018a). High pH in maple syrup is due to the filtration process, which removes sugar sand and organic acids, resulting in a higher $\mathrm{pH}$ compared to unfiltered maple syrup. Lower organic acids content is also attributed to the acid conversion to flavour compounds and maple syrup's mineral content (Stuckel \& Low, 1996) .

As alkaline $\mathrm{pH}$ favours formation of green pigments from amino group-chlorogenic acid interactions (Yabuta, Koizumi, Namiki, Hida, \& Namiki, 2001), the use of acidic dairy ingredients in baking could potentially decrease greening. Acidic dairy ingredients commonly used in bakery products, include yogurt, buttermilk, and sour cream (Dineen, Takeuchi, Soudah, \& Boor, 1998). Lactic acid fermentation of milk consumes carbohydrates such as lactose to produce lactic acid and lower the $\mathrm{pH}$ of dairy products such as yoghurt, sour cream and buttermilk (Shiby \& Mishra, 2013).

To eliminate greening of sunflower products, studies have focussed on separating the protein and CGA to minimize the green discolouration during protein extraction or during the application of sunflower protein (Pickardt, Eisner, Kammerer, \& Carle, 2015). Our approach was however, to leave both reactants in, and lower greening by formulation changes as reported by Liang and Were (2018a). Lower $\mathrm{pH}$ could affect CGA, lipid and protein oxidation, with interactions between CGA and protein potentially affecting both nutrition and appearance. As CGA is a phenolic antioxidant compound, its reducing capacity in sunflower butter cookies, in addition to its action as a reactant in the greening reaction, was investigated to determine how CGA-induced greening could affect the overall reducing capacity of cookies. The combined 
effects of typical acidic baking ingredients and storage time on greening of cookies, reducing capacity, Schiff bases and tryptophan were measured. This was done to determine potential impact of greening on nutrition, and reactants and products formed. Differences between two storage conditions (vacuum-sealed container and zip-lock bag) were also investigated to determine how oxygen post-baking affected greening of sunflower butter cookies.

\section{Materials and methods}

\subsection{Cookie formulation and baking conditions}

Sunflower butter dough (400 $\mathrm{g}$ in total) was formulated using all-purpose flour (39.7 \%), unsweetened and salt and sugar-free sunflower butter $(24.3 \%)$, egg (13\%), baking soda (0.6\%), vanilla extract $(0.6 \%)$, salt $(0.4 \%)$ and four acidic ingredients: honey and dairy ingredients $(21.4 \%)$ versus maple syrup. To eliminate moisture as a variable, which may enhance greening during baking and storage, the moisture of the four acidic ingredients was adjusted to that of maple syrup, which has approximately $32.03 \%$ water content (USDA, 2016). The same moisture content in cookie doughs was achieved by adding $13.73 \mathrm{~g}$ of water to honey and $50.60,55.14$, and $53.81 \mathrm{~g}$ of sucrose to sour cream, buttermilk and yogurt, respectively, according to the moisture content recorded in US Department of Agriculture (USDA), Branded Food Products Database, Release 28 document.

Two cookie dough batches for each treatment were prepared and mixed separately, rolled out and cut into $0.5 \pm 0.1 \mathrm{~cm}$ thick and $4.5 \mathrm{~cm}$ width cookie doughs, and baked at $177^{\circ} \mathrm{C}\left(350^{\circ} \mathrm{F}\right)$ for 7 min in a conventional oven (JA12SL, DOYON, Inc. Saint-Côme-Linière, Canada). The water activity, greening intensity and percentage greening were monitored after 1, 4, 8, 16, 24, and $72 \mathrm{~h}$. Moisture content, CGA, greening TBA, Folin-Coicalteu and ABTS-scavenging 
capacity and tryptophan and Schiff base fluorescence were tested before and after baking the cookies.

\section{2. $p H, a_{w}$, proximates (moisture, lipid, protein) and sugar content}

The $\mathrm{pH}$ of sweeteners and acidic ingredients ( $1 \mathrm{~g} / 4 \mathrm{ml}$ of deionized water), and dough and cookies mixtures $(0.5 \mathrm{~g} / 5 \mathrm{ml}$ of deionized water) was measured (AACC, 1999). Sample mixtures were homogenized at $6.8 \times 10^{2} * \mathrm{~g}$ for $45 \mathrm{~s}$, using a multi-prep rapid homogenizer (Multiprep Homogenizer, PRO Scientific Inc., Oxford, CT. USA) and incubated for $4 \mathrm{~h}$ before centrifugation at $4{ }^{\circ} \mathrm{C}$ and $3.3 \times 10^{3} * \mathrm{~g}$ for $30 \mathrm{~min}$, using a AccuSpin 1R-75003449 centrifuge (Thermo Fisher Scietific, Inc. CA. USA). The supernatant was collected to determine the pH of

cookies and doughs (AACC, 1999), using a Vernier ${ }^{\circledR} \mathrm{pH}$ sensor connected to Labquest 2 Version 2.7.1 software (Vernier Software \& Technology).

AACC method 44-15.02 (AACC, 1999) was used to measure the moisture content in doughs and cookies. Samples ( $3 \mathrm{~g}$ ) were placed in aluminium pans and put into a vacuum oven (Model 281, Thermo Fisher Scientific, Inc. CA. USA), kept at $60{ }^{\circ} \mathrm{C}$ and a pressure of $-70 \mathrm{kPa}$. The samples were taken out after $24 \mathrm{~h}$ and cooled in a desiccator for $5 \mathrm{~h}$. The mass of cookies was recorded before and after drying, and percentage difference in masses was used to calculate moisture content on a wet basis. The changes in $\mathrm{a}_{\mathrm{w}}$ were monitored using an AQUALAB water activity meter (Pullman, WA USA).

Lipid content was measured after Soxhlet extraction according to AACC method 30.26 (AACC, 1999). Crude protein of defatted and dehydrated samples was quantified using a nitrogen conversion factor of 5.7 according to AACC Method 46-12.01 (AACC, 1999), using a Kjeltec $^{\text {TM }} 8100$ system (Eden Prairie, MN USA). 
Sugar compositions of dehydrated-defatted cookies were quantified using HPLC at a column temperature of $70^{\circ} \mathrm{C}$ as described by Liang and Were (2018a) using standards prepared at $0-2.5 \mathrm{mg} / \mathrm{ml}$.

\subsection{Hunter $L^{*} a^{*} b^{*}$ and image analysis}

Greening was measured using a spectrophotometer (CM-2500d) equipped with SpectraMagic $\mathrm{NX}^{\circledR}$ colour data software (Konica Minolta, Inc. CA. USA) with the CIE L*a*b* system as described by Liang and Were (2018a and 2018b)

The percentage greening of cookies was carried out using an image analyzer (Keyence Corporation, CA. USA) equipped with a camera (CV-X422A) which had 2.0 megapixel. The percentage greening was calculated by equation 1, using Vision Database (CA-H1DB, Keyence Corporation, CA. USA).

$$
\text { percentage greening }=\frac{\text { Total green area }}{\text { Total cookie area }(\text { brown }+ \text { green area })} \times 100 \quad \text { (equation. }
$$

1)

Browning index (BI) was used to compare the internal browning of cookies after $0.25 \mathrm{~h}$ of baking and was calculated using equations 2 and 3 (Isleroglu et al., 2012).

$$
\text { Browning Index }=\frac{X-0.31}{0.17} \times 100
$$

where

$$
X=\frac{(a *+1.75 L *)}{5.645 L *+a *-3.012 b *}
$$

\subsection{Chlorogenic and caffeic acids, and tryhydroxyl benzacridine derivatives}

Chlorogenic acid and caffeic acid (Sigma-Aldrich, Saint Louis, MO. USA) standard solutions were prepared $(0.00-0.06 \mathrm{mg} / \mathrm{ml})$ in HPLC water. Sample solutions of doughs or cookies $\left(0.3 \mathrm{~g}\right.$ in $10 \mathrm{ml}$ of HPLC water) were homogenized at $0.68 \times 10^{3} \mathrm{~g}$ for $45 \mathrm{~s}$ and 
centrifuged at $3.3 * 10^{3} \mathrm{~g}$ for $30 \mathrm{~min}$ (AccuSpin 1R-75003449, Thermo Fisher Scientific, Inc. CA. USA) at $4{ }^{\circ} \mathrm{C}$. The solutions were filtered, using Whatman ${ }^{\circledR}$ glass microfibre filters (Grade GF/A circles, diam. $90 \mathrm{~mm}$ ), and then filtered, with a $0.45 \mu \mathrm{m}$ nylon syringe filter. The CGA of the supernatant was quantified, as decribed by Liang and Were (2018b). Chlorogenic acid-lysine standard solutions were prepared according to our previous study (Liang \& Were, 2018b) and TBA was quantified at $680 \mathrm{~nm}$, considering that all the CGA was reacted with lysine in the standard solutions. The results were expressed as mmol TBA/g cookies.

\subsection{Folin-Ciocalteu reagent and trolox equivalent antioxidant capacity}

The same supernatants and standards $(0.2 \mathrm{ml})$ as from the CGA quantification (section 2.4) were mixed with $0.1 \mathrm{M}$ Folin-Ciocalteu reagent $(1.5 \mathrm{ml})$. After $5 \mathrm{~min}$, the supernatants were neutralized, using $1.5 \mathrm{ml}$ of $\mathrm{Na}_{2} \mathrm{CO}_{3}(0.6 \mathrm{~g} / 10 \mathrm{ml}$ of deionized water $)$. Solutions were incubated for $30 \mathrm{~min}$ at room temperature (Liang \& Were, 2018a). The absorbance, at $760 \mathrm{~nm}$, of sample solutions was recorded, using a SpectroVis ${ }^{\circledR}$ plus spectrophotometer (Vernier Software \& Technology. USA).

TEAC assay was conducted according to Liang and Were (2018a). The results were expressed as nmol trolox/g cookies. Trolox (6-hydroxy-2,5,7,8-tetramethylchromane-2carboxylic acid), potassium peroxosulfate, and 2,2'-azinobis (3-ethylbenzothiazoline-6-sulfonic acid/ABTS), were purchased from Sigma-Aldrich (St. Louis, MO. USA) and ethanol was from Thermo Fisher Scientific (Huntington Beach, CA. USA). Trolox equivalent antioxidant capacity (TEAC) assay was used to measure the scavenging of $\mathrm{ABTS}^{\bullet+}$, as $\mathrm{ABTS}^{\bullet+}$ can fully dissolve in both organic and aqueous solutions with minimal interference by ionic strength, so multiple solvents can be used to test the antioxidant capacity for a complex food matrix, such as cookies. In contrast to the DPPH assay, which is also used in determination of antioxidant capacity in 
bakery foods, TEAC's ABTS ${ }^{\circ+}$ radical is also more light and temperature-stable than DPPH's radical (Marecek et al., 2017).

\subsection{Tryptophan and Schiff base fluorescence intensity}

Supernatants from ground dough and cookie mixtures $(0.3 \mathrm{~g} / 10 \mathrm{ml}$ of nano-filter water $)$ were incubated for $1 \mathrm{~h}$ before centrifugation and filtration using $0.45 \mu \mathrm{m}$ nylon filters. Tryptophan (Trp) and Schiff base fluorescence intensity (FI) of supernatants were recorded using a spectrofluorometer (Fluoromax ${ }^{\circledR}-4$, Horiba Scientific, CA. USA) with $\lambda_{\mathrm{ex}}=280 \mathrm{~nm}, \lambda_{\mathrm{em}}=300$ $500 \mathrm{~nm}$ and $\lambda_{\mathrm{ex}}=350 \mathrm{~nm}, \lambda_{\mathrm{em}}=380-600 \mathrm{~nm}$, respectively (Estevez, Kylli, Puolanne, Kivikari, \& Heinonen, 2008). The maximum intensity at $\lambda_{\max }=364 \mathrm{~nm}$ and $\lambda_{\max }=475 \mathrm{~nm}$ for $\operatorname{Trp}$ and Schiff bases, respectively, were normalized using the equation. 4 :

Normalized data $=\frac{\text { Intensity of treatment-minimum intensity of treatment }}{\text { Overall maximum intensity of treatment-minimum intensity of treatment }}$ (equation. 4)

\subsection{Statistical analysis}

The effects of treatments (maple syrup, honey, buttermilk, sour cream, and yoghurt), and storage time $(1,4,8,11,24$, and $72 \mathrm{~h})$ on greening of cookies, water activity, $\mathrm{pH}$, CGA content, TBA, Folin-Ciocalteu reducing capacity, ABTS-scavenging capacity, tryptophan and Schiff base fluorescence intensity were analyzed. Analysis of variance (ANOVA) with version 9.3 Statistical analysis software (, SAS institute Inc. NC. USA) and Duncan's multiple range test was used to determine level of the statistical significance of variables.

\section{Results and discussion}

\section{1. pH, $a_{w}$, proximates (moisture, lipid, protein) and sugar content}

The $\mathrm{pH}$ increased in cookies compared to the corresponding doughs, possibly due to release of carbon dioxide and increase in hydroxyl ions during baking (Tables 1 and 2; Gokmen, 
Acar, Serpen, \& Morales, 2008). After 1 h post-baking, the cookies made with honey had the lowest $\mathrm{pH}$ (7.84), while cookies made with maple syrup had the highest ( $\mathrm{pH}=8.69)$, with dairy containing cookies having a $\mathrm{pH}$ in between the two sweeteners. Differences in $\mathrm{pH}$ of cookies were attributed to initial $\mathrm{pH}$ differences of ingredients used, with a higher $\mathrm{pH}$ of the maple syrup compared to acid containing ingredients. The $\mathrm{pH}$ was strongly negatively correlated with Hunter a* $(r=-0.918, P<0.05$, supplementary materials Fig. S1A), which indicated that higher $\mathrm{pH}$, resulted in lower Hunter $\mathrm{a}^{*}$, which led to more internal greening in cookies.

All dough samples and all cookie samples had similar moisture contents (Table 1 and 2). This ruled out moisture as a variable in this study. Cookies made with sour cream had the highest lipid content (Table 2), which was consistent with a higher initial lipid content in sour cream (8.33\%), according to the US Department of Agriculture (USDA), Branded Food Products Database, Release 28 document.

Cookies made with maple syrup, yogurt and buttermilk had higher sugar contents than cookies made with sour cream. There was no reducing sugar (glucose, fructose or lactose) detected in cookies except in cookies made with honey, which had $42.4 \%$ and $49.6 \%$ glucose and fructose (Table 1), which resulted in more surface browning of cookies (supplementary materials Table 1; Ajandouz, Tchiakpe, Dalle Ore, Benajiba, \& Puigserver, 2001).

The $a_{w}$ values of cookies after baking and $24 \mathrm{~h}$ post storage were in the order: maple syrup $>$ sour cream $\approx$ buttermilk $>$ yogurt $>$ honey (Table 2 ). The higher reducing sugar content in honey caused a significant lowering in the water activity post-baking of cookies made with honey. Lower $\mathrm{a}_{\mathrm{w}}$ in cookies made with sour cream and yogurt compared to those with maple syrup could be due to their larger pore size (Table 2, supplementary materials Table S1) which may cause greater release of water vapour. More surface greening of cookies, after $24 \mathrm{~h}$ post - 
baking storage under higher humidity condition was observed (Table 2, Table S1) and $\mathrm{a}_{\mathrm{w}}$ decreased with time under the low relative humidity conditions $(21 \% \mathrm{RH})$ of storage, which was consistent with our previous study (Liang \& Were, 2018b).

\subsection{Greening and browning in cookies}

Monitoring of Hunter $-\mathrm{a}^{*}$ and $-\mathrm{b}^{*}$ values, which are important indices for evaluating green to blue colour changes that complemented the percentage greening, using an image analyzer was initially done to compare different oxygen storage conditions (vacuum versus Ziploc $®$ bags) post-baking. Under vacuum storage conditions, the $a^{*}$ values were not significantly different from those of cookies stored in Ziploc® bags, because CGA quinone formation, needed for greening, promoted by the presence of oxygen, had probably mostly occurred during baking at high temperature. The differences in cookies stored under vacuum compared to those exposed to oxygen post-baking were negligible over the duration of storage, so subsequent trials omitted storage of cookies under vacuum (supplemental material Fig. S2).

Cookies made with maple syrup as a greening control had the highest percentage internal greening and greening intensity (Table 2, supplementary material Table S1, Fig. S1) and turned blue-green after $16 \mathrm{~h}$ (Table. 2, Fig. 1D). The order of internal greening was: cookies made with maple syrup>sour cream $>$ buttermilk>yoghurt>honey (Fig. 1), which was due to the highest $\mathrm{pH}$ in maple syrup (Table 1 and 2) that favoured greening (Liang \& Were 2018a, 2018b). The low $\mathrm{pH}$ of honey is due to organic acids, such as gluconic, citric, levulinic, and formic acids (da Silva, Gauche, Gonzaga, Costa, \& Fett, 2016). This higher acidity did not favour green pigment formation, as also illustrated by the the suppression of green derivatives measured at $680 \mathrm{~nm}$ (Table 1). The observed $A_{\max }$ at $680 \mathrm{~nm}$, in the lysine-chlorogenic acid adducts solution, was attributed to trihydroxy benzacridine (TBA) derivatives, consistent with observations in model 
systems (Iacomino et al., 2017), in our previous study (Liang \& Were, 2018b), and that of cookies in the current study (Table 2, Fig. 1, supplementary materials Table S1). Lysine crosslinking with CGA has been associated with higher green pigment formation, as the $\varepsilon$-amino side group of lysine makes it highly reactive in the greening reaction (Bongartz et al., 2016). The dairy ingredients had a decolourizing effect, but they were generally not as effective as honey in preventing greening, attributed to the higher initial $\mathrm{pH}$ of dairy ingredients when compared to honey (Table 1).

The increase in absorbance at $680 \mathrm{~nm}$ corroborated with image analysis and the Hunter $\mathrm{a}^{*}$ values (Table 1, Fig. 1), with the higher $\mathrm{pH}$ ingredients resulted in more greening in sunflower butter cookies, corresponding to formation of the green TBA pigment (Yabuta et al., 2001; Liang \& Were, 2018b), with maximum absorbance at $680 \mathrm{~nm}$ (supplementary materials Fig. S1D). The greening observed in the cookies results from the alkaline conditions caused by high $\mathrm{pH}$ ingredients (baking soda and maple syrup), favouring oxidation of CGA in the sunflower seed butter and subsequently reacting with amino acids (Bongartz et al., 2016).

In addition to the effect of $\mathrm{pH}$, greening intensity and percentage green cookie area increased with time, and cookies made with maple syrup had nearly $100 \%$ green area coverage after $24 \mathrm{~h}$ (Table 2, supplementary materials Table S1). The changes in greening over time were rapid in the first $8 \mathrm{~h}$, with a rate of 1.2 to 5.7 percentage internal greening per hour, in cookies made with maple syrup and dairy ingredients, where greening displaced the brown regions on the cookies. The cookies made with honey, however, were not green (Table 2, Fig. 1, supplementary materials Table S1). Increased greening over time may have occurred due to increased contact time between reactants. Higher internal greening of cookies compared to surface greening (Fig.1) was due to greater moistness in the interior compared to the top or bottom of the cookies consistent with our earlier findings (Liang \& Were, 2018b). 
The browning of cookies could have been from oxidized CGA reacting with amines and other polyphenols, or with itself (Bongartz et al., 2016). The reducing sugar content in honey also contributed to the browning through the Maillard reaction. The internal browning index (BI) of cookies showed BIs of 76.2, 76.7, 78.3, 76.8 and 80.2 in cookies formulated with maple syrup, sour cream, buttermilk, yoghurt and honey, $1 \mathrm{~h}$ post-baking, respectively. The BI indicated that cookies made with honey had the most browning (Isleroglu et al., 2012; Table 2 and supplementary materials Table S1). In addition, cookies made with honey had the highest $\mathrm{A}_{294} / \mathrm{A}_{420}$ ratio, which indicated more Maillard Schiff bases compared to melanoid polymers after 1 h post-baking (Table 1; Ajandouz, Tchiakpe, Dalle Ore, Benajiba, \& Puigserver, 2001) that resulted in more browning compared to other cookies.

Given the presence of protein, carbohydrates and phenolic compounds in various foods, there are various colour reactions that occur simultaneously during baking. Some of the key reactants, such as CGA, are similar for both Maillard browning and greening reactions. Browning differences observed were attributed to differences in types of sugars. Cookies made with honey was comprised of approximately $92 \%$ reducing sugars (Table 1), while maple syrup and the cookies made with dairy ingredients had sucrose, a non Maillard reactive sugar as the main sweetener (St-Pierre et al., 2014). This resulted in cookies made with honey having greater surface browning that resembled gingerbread snap cookies in colour, in contrast to a lighter colour in other cookies where sucrose would need to be inverted by acid and/or heat to participate in Maillard browning reactions (Golon, Kropf, Vockenroth, \& Kuhnert, 2014).

\subsection{Changes in chlorogenic acid and protein content}

There were no significant differences among the CGA contents of all the doughs $(P=$ 0.19), which was attributed to the same amount of sunflower butter in all cookie formulations. 
After baking, cookies had a lower CGA content due to CGA reacting with the amino groups to form TBA derivatives, and Maillard reaction products after baking (Narita \& Inouye, 2013; Yabuta et al., 2001). The ratio of CGA to its hydrolysis product (caffeic acid/CA) in cookies made with maple syrup, sour cream, buttermilk, yogurt, and honey decreased after baking compared to their corresponding doughs (Table 1). This indicated the loss of CGA (forming CA) during heating. Cookies made using maple syrup, sour cream, and buttermilk had lower CGA after baking, while cookies made with honey and yogurt had higher CGA (Table 1, Fig. 2), which was attributed to their lower $\mathrm{pH}$. Chlorogenic acid dimers oxidize, leading to $o$-quinones formation, which readily react with amino groups to form TBA derivatives (Yabuta et al., 2001). These reactions lead to the loss of CGA in favour of increased CGA- amino acid adduct contents (Table 1, Bongartz et al., 2016; Narita \& Inouye, 2013),

Cookies made with sour cream had the highest protein content, as expected (Table 2), based on amounts used in our cookie formulations and published higher protein contents in dairy ingredients of $6.7,3.3$, and $4.7 \mathrm{~g} / 100 \mathrm{~g}$ in sour cream, buttermilk and yogurt, respectively (USDA, 2016).

3.4. Folin-Ciocalteu reagent reducing and trolox equivalent antioxidant capacity (TEAC) assay

Doughs made with honey after $1 \mathrm{~h}$ had the highest Folin-Ciocalteu reagent/FCR reducing capacity (Fig. 3A) due to its higher reducing capacity (from the phenols) and highest reducing sugar content (Ball, 2007). After 24 h of storage, the FCR reducing capacities were similar in doughs. However, cookies made with honey had a significant increase in FCR reducing capacy due to the production of intermediate and/or final Maillard reaction products (Fig. 3A; Gu, Kim, Hayat, Xia, Feng, \& Zhang, 2009; Michalska, Amigo-Benavent, Zielinski, \& del Castillo, 2008). 
The FCR reducing capacity decreased after baking, except in cookies made with honey, where it increased. Amongst the treatments, cookies made with yogurt and honey had higher FCR reducing capacity, as these were the treatments with less greening due to their lower $\mathrm{pH}$ (Table 1 and 2). The loss of FCR reducing capacity in cookies made with maple syrup, sour cream and butter milk was due to the loss of CGA, which oxidized and bound with amino groups and formed TBA (Bongartz et al., 2016). Cookies, after $24 \mathrm{~h}$ of storage, had similar FCR reducing capacity to cookies after $1 \mathrm{~h}$ of storage, due to continual Maillard reaction with MRPs compensating for the loss of CGA (Gu et al., 2009; Michalska et al., 2008).

The antioxidant capacities (AOX) of all doughs after $1 \mathrm{~h}$ were similar except for doughs made with maple syrup, which had lower AOX (Fig. 3B). Similar to FCR reducing capacity, the loss of AOX in doughs made with maple syrup after $1 \mathrm{~h}$ of storage was due to oxidized CGA at higher $\mathrm{pH}$ reacting with protein (Liang \& Were, 2018b). Cookies after 1 and 24 h post-baking storage had higher AOX compared to their corresponding doughs (Fig. 3B). Increased AOX in cookies was caused by reducing capacity of formed MRPs (Ateea, Omayma, Mohammed, \& Ahmed, 2012)

\subsection{Tryptophan fluorescence intensity}

To complement the TBA derivative complexes measured at 680nm, intrinsic Trp fluorescence was measured to further confirm conjugation between the protein-containing ingredients (sunflower, egg and/or dairy ingredients), chlorogenic acid and sugars. Most of the tryptophan would be expected to come from the egg used which was the same in all formulations. Solutions of the sweeteners and acidic dairy ingredients in the ratios present in the dough were first brought to the same moisture content by adding water to honey and sucrose to the dairy ingredients, prior to heating, to determine their role in the overall Trp fluorescence 
intensity (FI) in the cookies. As expected, the dairy ingredients had a higher Trp FI compared to the sweeteners (Supplementary materials Fig. S3A).

When doughs were tested, the addition of dairy ingredients increased initial Trp FI as the dairy containing dough had higher initial Trp FI when unheated (Fig. 4A). The $\lambda_{\max }$ emission wavelength was $364 \pm 1 \mathrm{~nm}$ for all treatments, except for cookies made with honey which had a slight red shift with $\lambda_{\max }$ at $367 \mathrm{~nm}$, accompanied by higher FI (supplementary material Fig. S3). Doughs, after $24 \mathrm{~h}$ storage, had decreased FI, attributed to Trp oxidation during storage.

Decreased Trp FI could also be due to covalently-bound protein-polysaccharide complexes that have been noted to be more hydrophilic than is unbound protein; therefore, they will have lower electron excitation due to quenching and thus, lower electron excitation due to quenching ( $\mathrm{Gu} \&$ Kenny, 2009). The FI of doughs after $24 \mathrm{~h}$ of storage and baking decreased, due to conjugate formation during Maillard reaction (Wang \& Xiong, 2016).

Cookies tested after 1 and 24 h of storage had lower Trp FI than had their corresponding doughs. Trp FI decrease with baking was due to the various heat-induced reactions. In addition, the Trp FI decreased with increased pH (Fig. 4A), attributed to the oxidation of Trp, which is favoured under high $\mathrm{pH}$ conditions (Liang \& Were, 2018a). Direct glycation of reducing sugars with the Trp indole group has been noted to destroy Trp in cookies when glucose rather than sucrose was used in baking (Morales, Acar, Serpen, Arribas-Lorenzo, \& Gokmen, 2007). Our results, however, showed that cookies with sucrose as the main sweetener had lower Trp FI. These cookies with lower Trp, excepting those with maple syrup, had dairy as an ingredient, so this was possibly due to the fat oxidation products from added dairy ingredients interacting with Trp (Table 1; Horvatic \& Vedrina-Dragojevic, 2000). To what extent this hypothesis is valid 
needs to be further investigated to distinguish the contribution of Trp FI quenching from the various concurrent reactions taking place with heat.

\subsection{Schiff base formation}

Schiff base FI values in dough amongst the different treatments after 1 and $24 \mathrm{~h}$ of storage were similar (Table 1, Fig. 4B). After baking, cookies made with honey had the highest Schiff bases while cookies made with sour cream had the lowest after $1 \mathrm{~h}$ of storage. Higher Schiff bases could be from protein and lipid oxidation, along with Maillard reaction (Charissou et al., 2007; Yamaki, Kato, \& Kikugawa, 1992). Cookies made with honey had the most reducing sugar and resulted in more Schiff bases forming from the Maillard reaction. In addition, higher $\mathrm{pH}$, as observed in the doughs and cookies made with maple syrup, creates a favourable condition for formation of Schiff bases (Ajandouz, Tchiakpe, Dalle Ore, Benajiba, \& Puigserver, 2001). Schiff bases are, however, an intermediate product of the Maillard reaction, and the higher reducing sugars may have resulted in the high Schiff bases observed initially in the cookies made with honey, which later declined after $24 \mathrm{~h}$ due to Schiff bases participating in further Maillard reactions (Fig. 4). The lower $\mathrm{pH}$ of cookies made with the dairy ingredients or honey, may have contributed to lower Schiff bases in cookies after $24 \mathrm{~h}$, given that baking time and temperature, leavening agent and moisture contents were similar.

\section{Conclusions}

The results suggest that it is possible to decrease greening with changes in formulation and by limiting storage time to address concerns about greening in sunflower butter when it is used as a replacement for allergen containing plant butters. Honey which had the lowest $\mathrm{pH}$ and $\mathrm{a}_{\mathrm{w}}$ of the investigated acidic ingredients, prevented post-baking greening to the greatest extent. The cookies made with honey were, however, darker brown, which was attributed to their higher 
reducing sugar content, despite their lack of surface and internal greening. Further research could focus on sensory evaluation and consumer acceptance of green sunflower butter cookies. The effects of greening induced oxidation on the levels of other Maillard reaction products, such as acrylamide and HMF concentrations, should be assessed to optimize formulations for lowering of green pigment formation and enhancing nutrition to complement sensory effects (taste, mouthfeel and potential aftertaste).

\section{Conflict of interest}

There are no conflicts of interest to declare.

\section{Acknowledgements}

The authors would like to thank Chapman University for financially supporting this research, and Pham Vu with the preliminary data collection.

\section{References}

AACC (1999). Method 02-52.01. Hydrogen-Ion Activity (pH) -- Electrometric Method, Method 44-15.02: Moisture-Air-Oven, Method method 30.26: Lipid content, Method 46-12.01: Baked products total protein content (11th ed.). St. Paul, MN, U.S.A.

Ajandouz, E. H., Tchiakpe, L. S., Dalle Ore, F., Benajiba, A., \& Puigserver, A. (2001). Effects of $\mathrm{pH}$ on caramelization and Maillard reaction kinetics in fructose-lysine model systems. Journal of Food Science, 66(7), 926-931.

Ateea, A., Bellail, Omayma, E., Shaltout, Mohammed, M., Youssef, \& Ahmed, M. E., Gamal (2012). Effect of home-cooking methods on phenolic composition and antioxidant activity of sweetpotato (Ipomoea batatas (L.) Lam.) cultivars grown in Egypt. Food and Nutrition Sciences, 2012, 3, 490-499

Ball, D. W. (2007). The chemical composition of honey and maple syrup. Journal of Chemical Education, 84(10), 1643-1650.

Bongartz, V., Brandt, L., Gehrmann, M. L., Zimmermann, B. F., Schulze-Kaysers, N., \& Schieber, A. (2016). Evidence for the Formation of Benzacridine Derivatives in AlkalineTreated Sunflower Meal and Model Solutions. Molecules, 21(1), 91-95.

Boyce, J. A., Assa'a, A., Burks, A. W., Jones, S. M., Sampson, H. A., Wood, R. A., et al. (2011). Guidelines for the diagnosis and management of food allergy in the United States: Summary of the NIAID-Sponsored Expert Panel Report. Nutrition, 27(2), 253-267.

Charissou, A., Ait-Ameur, L., \& Birlouez-Aragon, I. (2007). Kinetics of formation of three indicators of the maillard reaction in model cookies: Influence of baking temperature and type of sugar. Journal of Agricultural and Food Chemistry, 55(11), 4532-4539. 
da Silva, P. M., Gauche, C., Gonzaga, L. V., Costa, A. C. O., \& Fett, R. (2016). Honey: Chemical composition, stability and authenticity. Food Chemistry, 196, 309-323.

Dineen, S. S., Takeuchi, K., Soudah, J. E., \& Boor, K. J. (1998). Persistence of Escherichia coli O157 : H7 in dairy fermentation systems. Journal of Food Protection, 61(12), 16021608.

Dorrell, D. G., \& Vick, B. A. (1997). Properties and processing of oilseed sunflower. Wisconsin: American Society of Agronomy, 709-744.

Estevez, M., Kylli, P., Puolanne, E., Kivikari, R., \& Heinonen, M. (2008). Fluorescence spectroscopy as a novel approach for the assessment of myofibrillar protein oxidation in oil-in-water emulsions. Meat Science, 80(4), 1290-1296.

Gokmen, V., Acar, O. C., Serpen, A., \& Morales, F. J. (2008). Effect of leavening agents and sugars on the formation of hydroxymethylfurfural in cookies during baking. European Food Research and Technology, 226(5), 1031-1037.

Golon, A., Kropf, C., Vockenroth, I., \& Kuhnert, N. (2014). An Investigation of the Complexity of Maillard Reaction Product Profiles from the Thermal Reaction of Amino Acids with Sucrose Using High Resolution Mass Spectrometry. Foods (Basel, Switzerland), 3(3), 461-475.

Gu, F. L., Kim, J. M., Hayat, K., Xia, S. Q., Feng, B. A., \& Zhang, X. M. (2009). Characteristics and antioxidant activity of ultrafiltrated Maillard reaction products from a casein-glucose model system. Food Chemistry, 117(1), 48-54.

Gu, Q., \& Kenny, J. E. (2009). Improvement of Inner Filter Effect Correction Based on Determination of Effective Geometric Parameters Using a Conventional Fluorimeter. Analytical Chemistry, 81(1), 420-426.

Horvatic, M., \& Vedrina-Dragojevic, I. (2000). Changes in available methionine and tryptophan contents during cereal flake production. Journal of the Science of Food and Agriculture, $80(4), 502-506$.

Hsu, D. C., \& Katelaris, C. H. (2007). Is "nut-free" sunflower seed butter safe for children with peanut allergy? Medical Journal of Australia, 187(9), 542-543.

Iacomino, M., Weber, F., Gleichenhagen, M., Pistorio, V., Panzella, L., Pizzo, E., et al. (2017). Stable Benzacridine Pigments by Oxidative Coupling of Chlorogenic Acid with Amino Acids and Proteins: Toward Natural Product-Based Green Food Coloring. Journal of Agricultural and Food Chemistry, 65(31), 6519-6528

Isleroglu, H., Kemerli, T., Sakin-Yilmazer, M., Guven, G., Ozdestan, O., Uren, A., et al. (2012). Effect of Steam Baking on Acrylamide Formation and Browning Kinetics of Cookies. Journal of Food Science, 77(10), E257-E263.

Labuza, T. P., \& Hyman, C. R. (1998). Moisture migration and control in multi-domain foods. Trends in Food Science \& Technology, 9(2), 47-55.

Liang, S., \& Were, L. M. (2018a). Chlorogenic acid induced colored reactions and their effect on carbonyls, phenolic content, and antioxidant capacity in sunflower butter cookies. $L W T$ Food Science and Technology, 87, 16-22.

Liang, S., \& Were, L. M. (2018b). Chlorogenic acid oxidation-induced greening of sunflower butter cookies as a function of different sweeteners and storage conditions. Food Chemistry, 241, 135-142.

Marecek, T., Mikyska, A., Hampel, D., Cejka, P., Neuwirthova, J., Malachova, A., et al. (2017). ABTS and DPPH methods as a tool for studying antioxidant capacity of spring barley and malt. Journal of Cereal Science, 73, 40-45. 
Michalska, A., Amigo-Benavent, M., Zielinski, H., \& del Castillo, M. D. (2008). Effect of bread making on formation of Maillard reaction products contributing to the overall antioxidant activity of rye bread. Journal of Cereal Science, 48(1), 123-132.

Morales, F. J., Acar, O. C., Serpen, A., Arribas-Lorenzo, G., \& Gokmen, V. (2007). Degradation of free tryptophan in a cookie model system and its application in commercial samples. Journal of Agricultural and Food Chemistry, 55(16), 6793-6797.

Narita, Y., \& Inouye, K. (2013). Degradation Kinetics of Chlorogenic Acid at Various pH Values and Effects of Ascorbic Acid and Epigallocatechin Gallate on Its Stability under Alkaline Conditions. Journal of Agricultural and Food Chemistry, 61(4), 966-972.

Nwaru, B. I., Hickstein, L., Panesar, S. S., Roberts, G., Muraro, A., Sheikh, A., et al. (2014). Prevalence of common food allergies in Europe: a systematic review and meta-analysis. Allergy, 69(8), 992-1007.

Pickardt, C., Eisner, P., Kammerer, D. R., \& Carle, R. (2015). Pilot plant preparation of lightcoloured protein isolates from de-oiled sunflower (Helianthus annuus L.) press cake by mild-acidic protein extraction and polyphenol adsorption. Food Hydrocolloids, 44, 208219.

Shiby, V. K., \& Mishra, H. N. (2013). Fermented Milks and Milk Products as Functional FoodsA Review. Critical Reviews in Food Science and Nutrition, 53(5), 482-496.

Sicherer, S. H., Munoz-Furlong, A., Godbold, J. H., \& Sampson, H. A. (2010). US prevalence of self-reported peanut, tree nut, and sesame allergy: 11-year follow-up. Journal of Allergy and Clinical Immunology, 125(6), 1322-1326.

St-Pierre, P., Pilon, G., Dumais, V., Dion, C., Dubois, M.-J., Dube, P., et al. (2014). Comparative analysis of maple syrup to other natural sweeteners and evaluation of their metabolic responses in healthy rats. Journal of Functional Foods, 11, 460-471.

Stuckel, J. G., \& Low, N. H. (1996). The chemical composition of 80 pure maple syrup samples produced in North America. Food Research International, 29(3-4), 373-379.

USDA (2016). United States Department of Agriculture. Basic Report 19353, Syrups, maple. Agriculture Research Service. National Nutrient Database for Standard Reference Release 28. from https://ndb.nal.usda.gov/ndb/foods/show/6329?manu=\&fgcd=\&ds= Accessed 05.12.17

Wang, X., \& Xiong, Y. L. L. (2016). Oxidative polyaldehyde production: a novel approach to the conjugation of dextran with soy peptides for improved emulsifying properties. Journal of Food Science and Technology-Mysore, 53(8), 3215-3224.

Weisz, G. M., Kammerer, D. R., \& Carle, R. (2009). Identification and quantification of phenolic compounds from sunflower (Helianthus annuus L.) kernels and shells by HPLCDAD/ESI-MS ${ }^{\mathrm{n}}$. Food Chemistry, 115(2), 758-765.

Wildermuth, S. R., Young, E. E., \& Were, L. M. (2016). Chlorogenic Acid Oxidation and Its Reaction with Sunflower Proteins to Form Green-Colored Complexes. Comprehensive Reviews in Food Science and Food Safety, 829-843.

Yabuta, G., Koizumi, Y., Namiki, K., Hida, M., \& Namiki, M. (2001). Structure of green pigment formed by the reaction of caffeic acid esters (or chlorogenic acid) with a primary amino compound. Bioscience Biotechnology and Biochemistry, 65(10), 2121-2130.

Yamaki, S., Kato, T., \& Kikugawa, K. (1992). Characteristics of Fluorescence Formed by the Reaction of Proteins with Unsaturated Aldehydes, Possible Degradation Products of Lipid Radicals. Chemical \& Pharmaceutical Bulletin, 40(8), 2138-2142. 


\section{Figure Captions}

Fig. 1. Changes in water activity (A), percent greening (B), Hunter $a^{*}(C)$, and $b^{*}$ values (D) with time.

Fig. 2. Changes in chlorogenic and caffeic acid in sunflower butter doughs (A) and cookies (B).

Fig. 3. Folin-Ciocalteau Reagent reducing capacity (A) and trolox equivalent antioxidant capacity (B) of sunflower butter doughs and cookies at different storage times.

Fig. 4. Normalized fluorescence intensity of tryptophan at $\lambda_{\max }=356 \mathrm{~nm}(\mathrm{~A})$ and Schiff bases at $\lambda_{\max }=475 \mathrm{~nm}(\mathrm{~B})$. 
A) water activity changes along with time

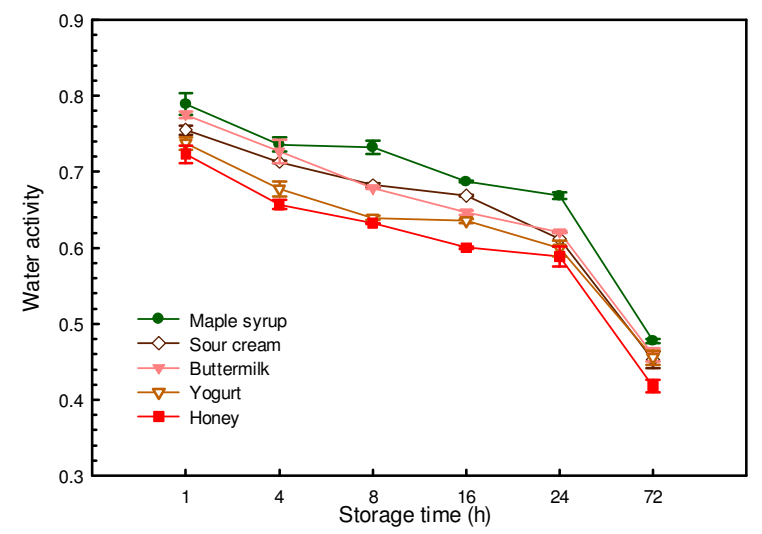

C) Cookie internal Hunter a* value changes along with time

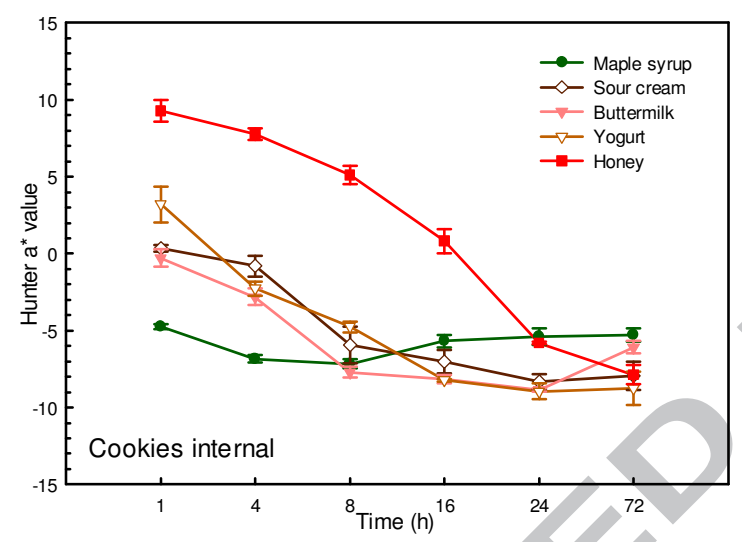

Fig. 1.
B) \% greening changes along with time

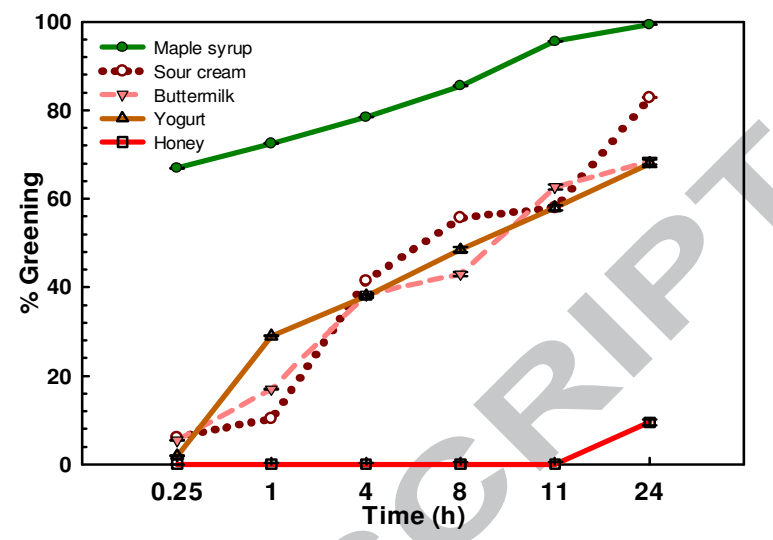

D) Cookie internal Hunter $b *$ value changes along with time

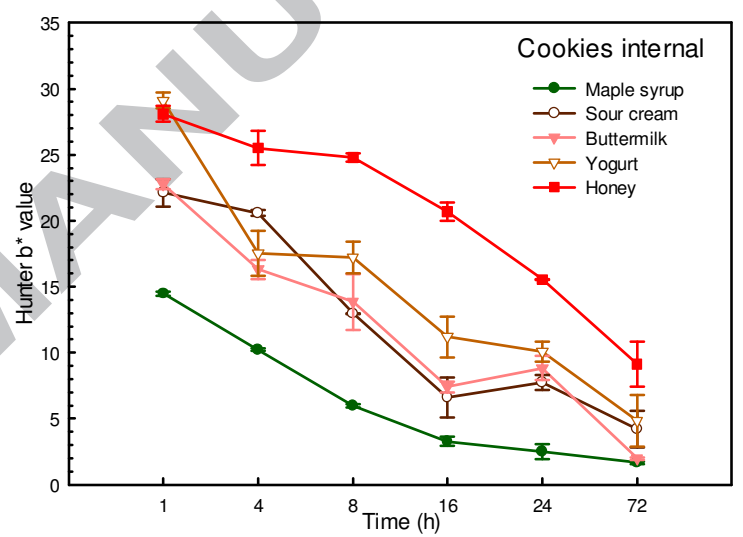


A) Doughs after $1 \mathrm{~h}$ storage

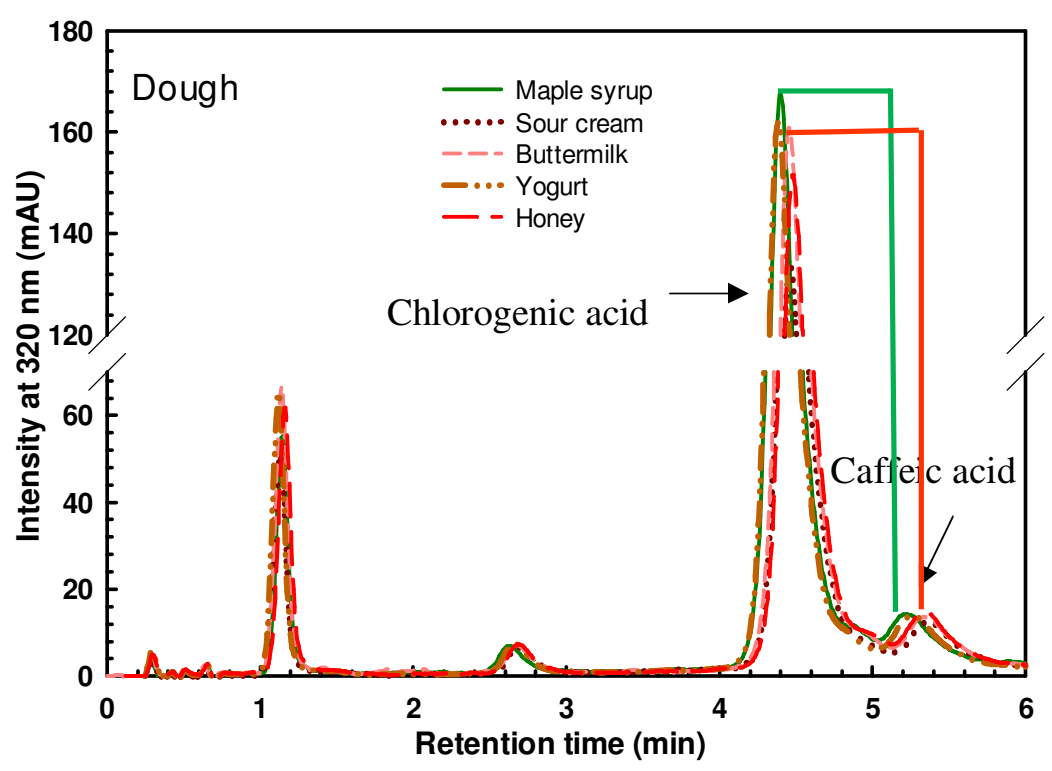

B) Cookies after $1 \mathrm{~h}$ storage

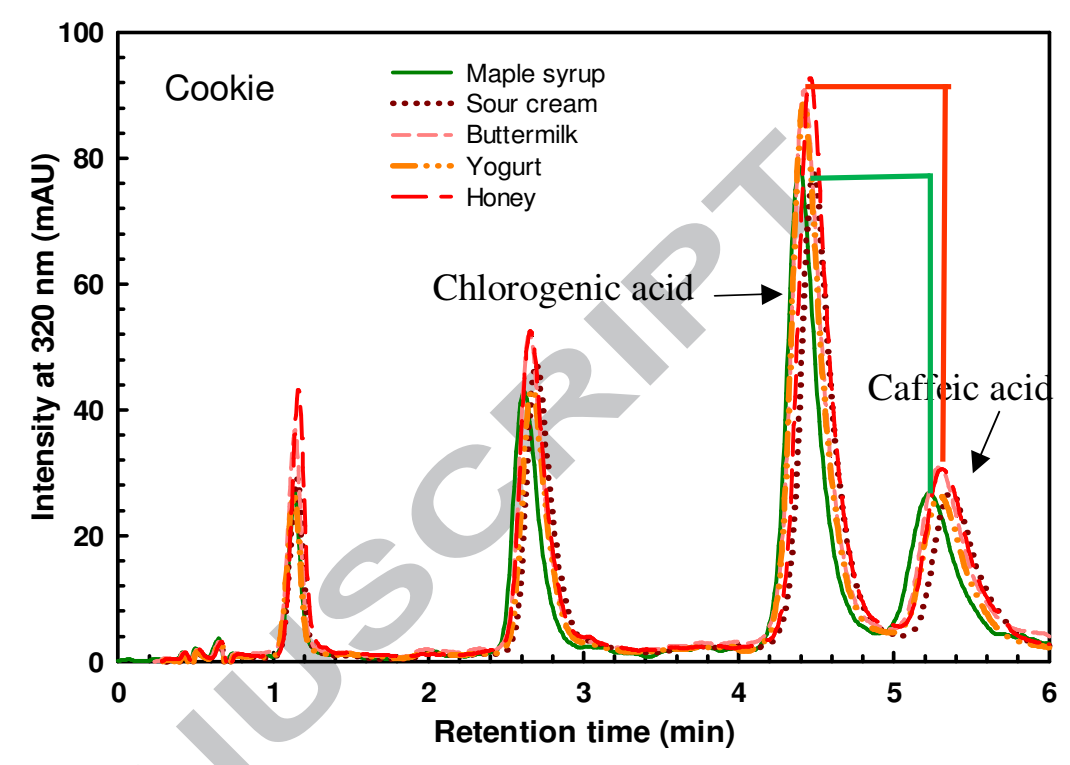

Fig. 2. 
A) Folin-Ciocalteau reagent reducing capacity in doughs and cookies after 1 and $24 \mathrm{~h}$

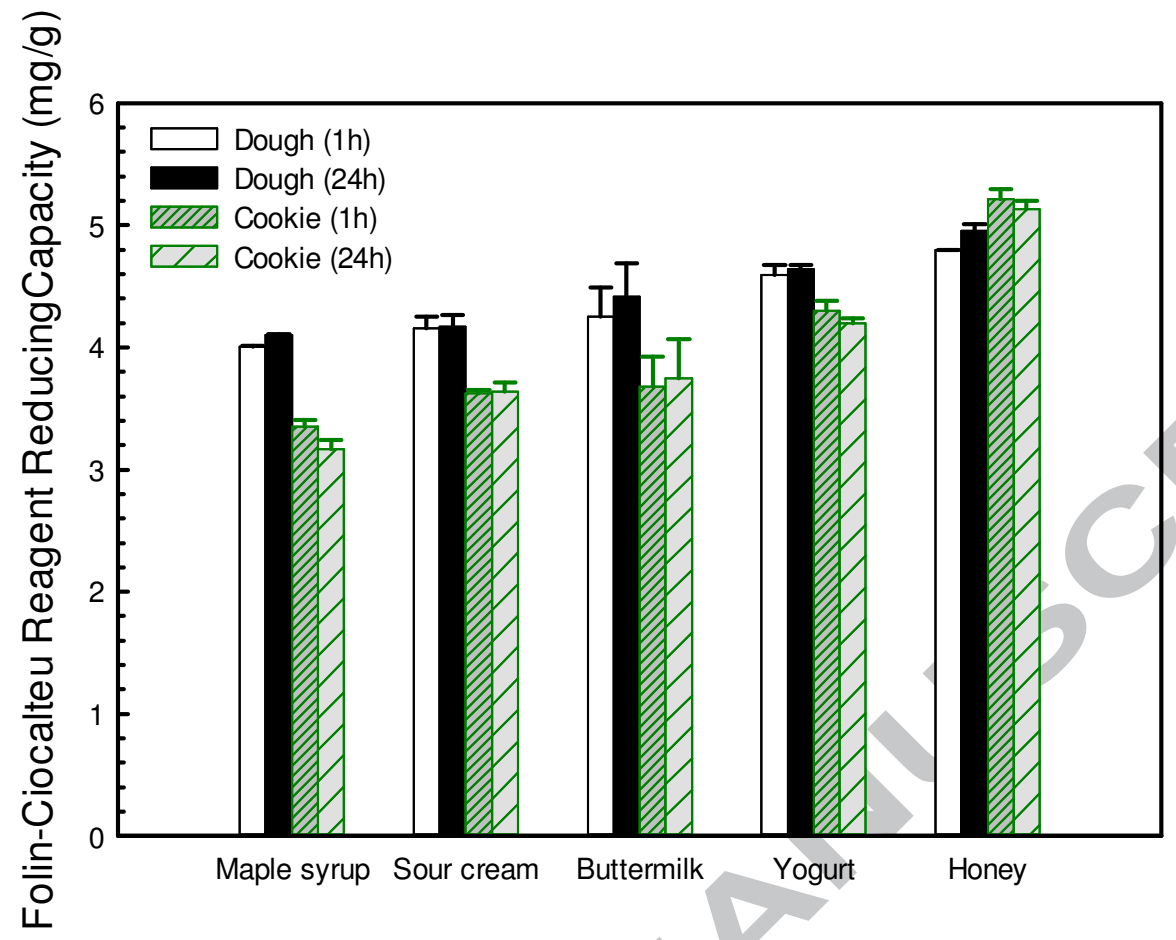

B) Trolox equivalent antioxidant capacity in doughs and cookies after 1 and $24 \mathrm{~h}$ storage

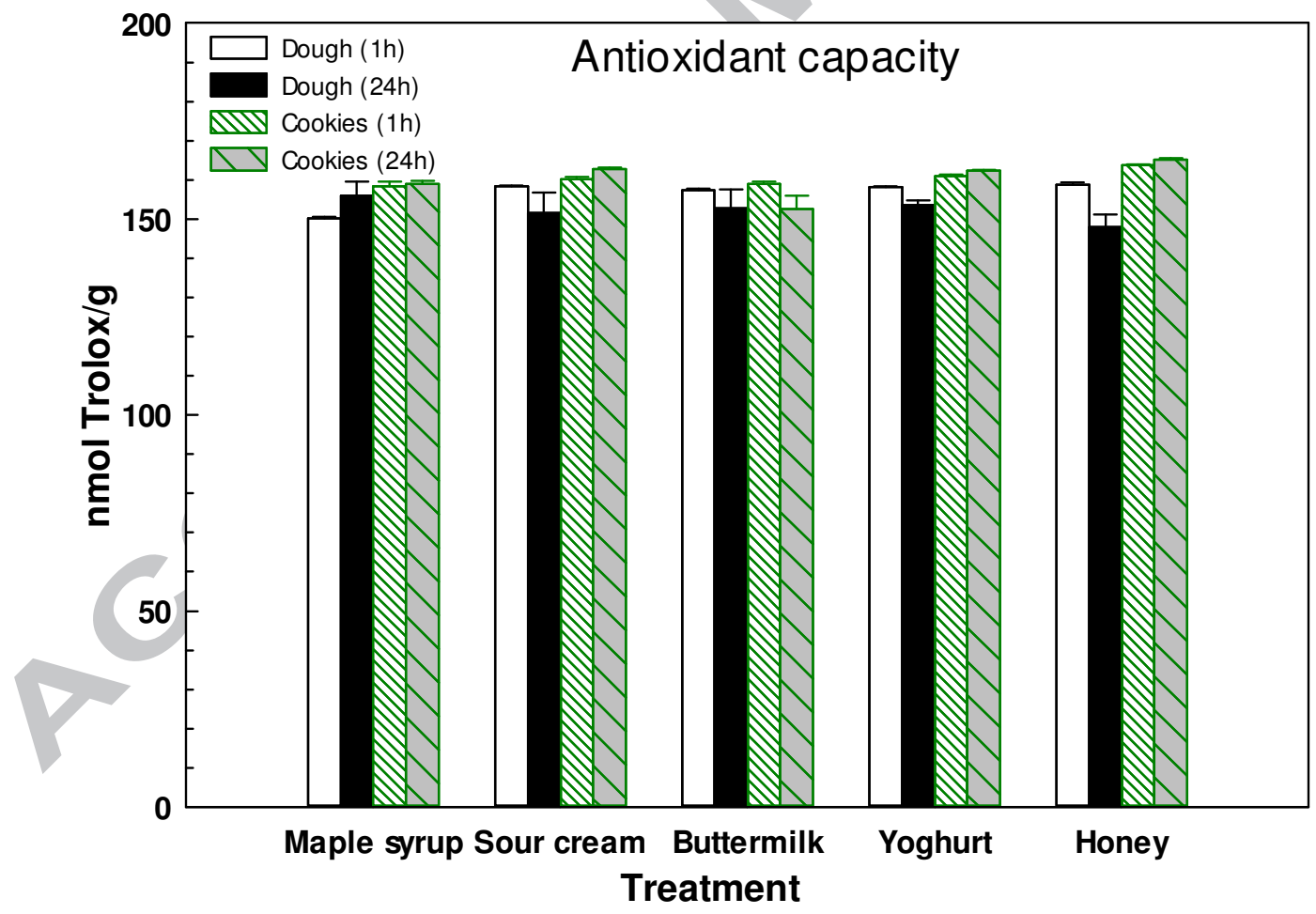

Fig. 3. 
A) Tryptophan fluorescence intensity of doughs and cookies after 1 and $24 \mathrm{~h}$ storage

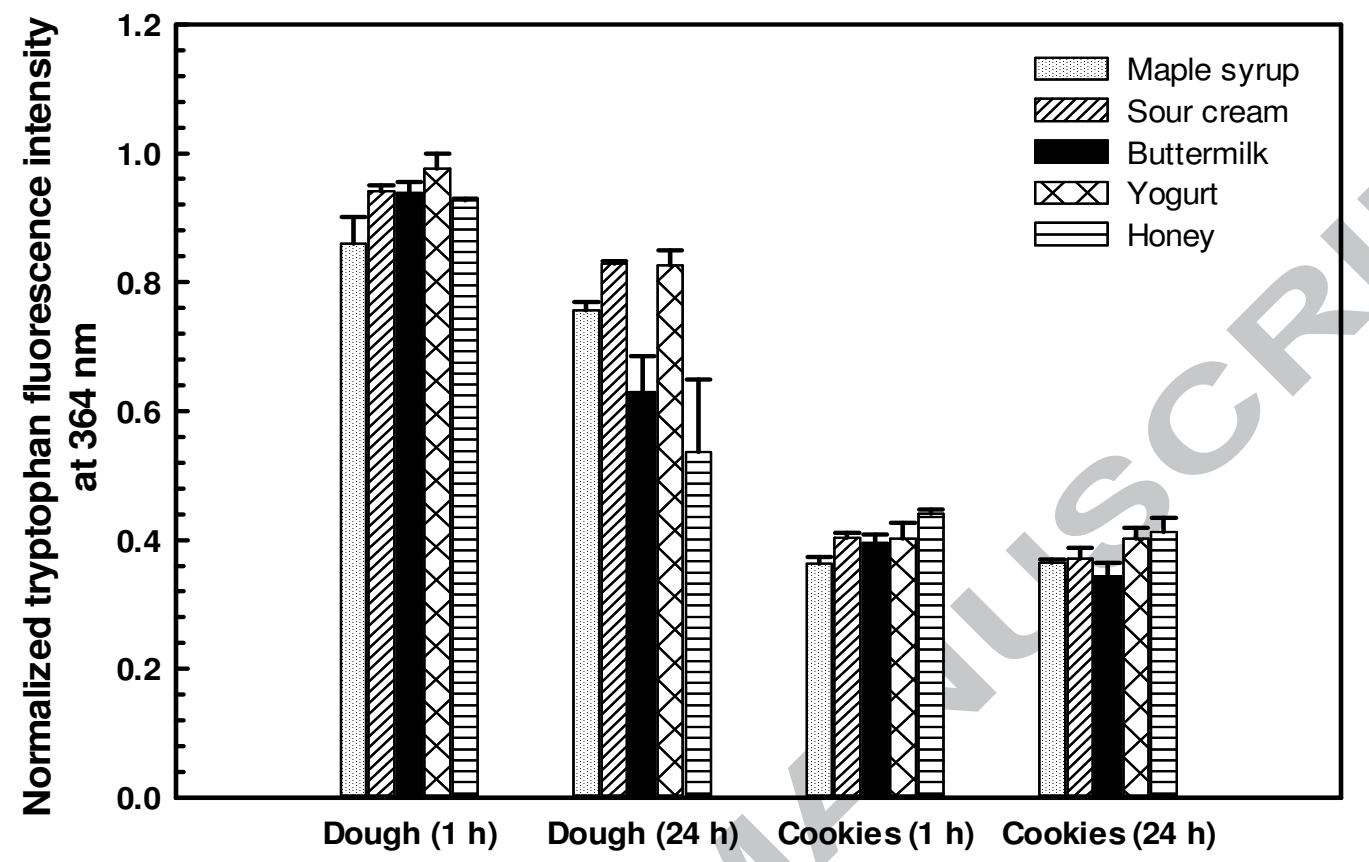

B) Schiff bases fluorescence intensity of doughs and cookies after 1 and $24 \mathrm{~h}$ storage

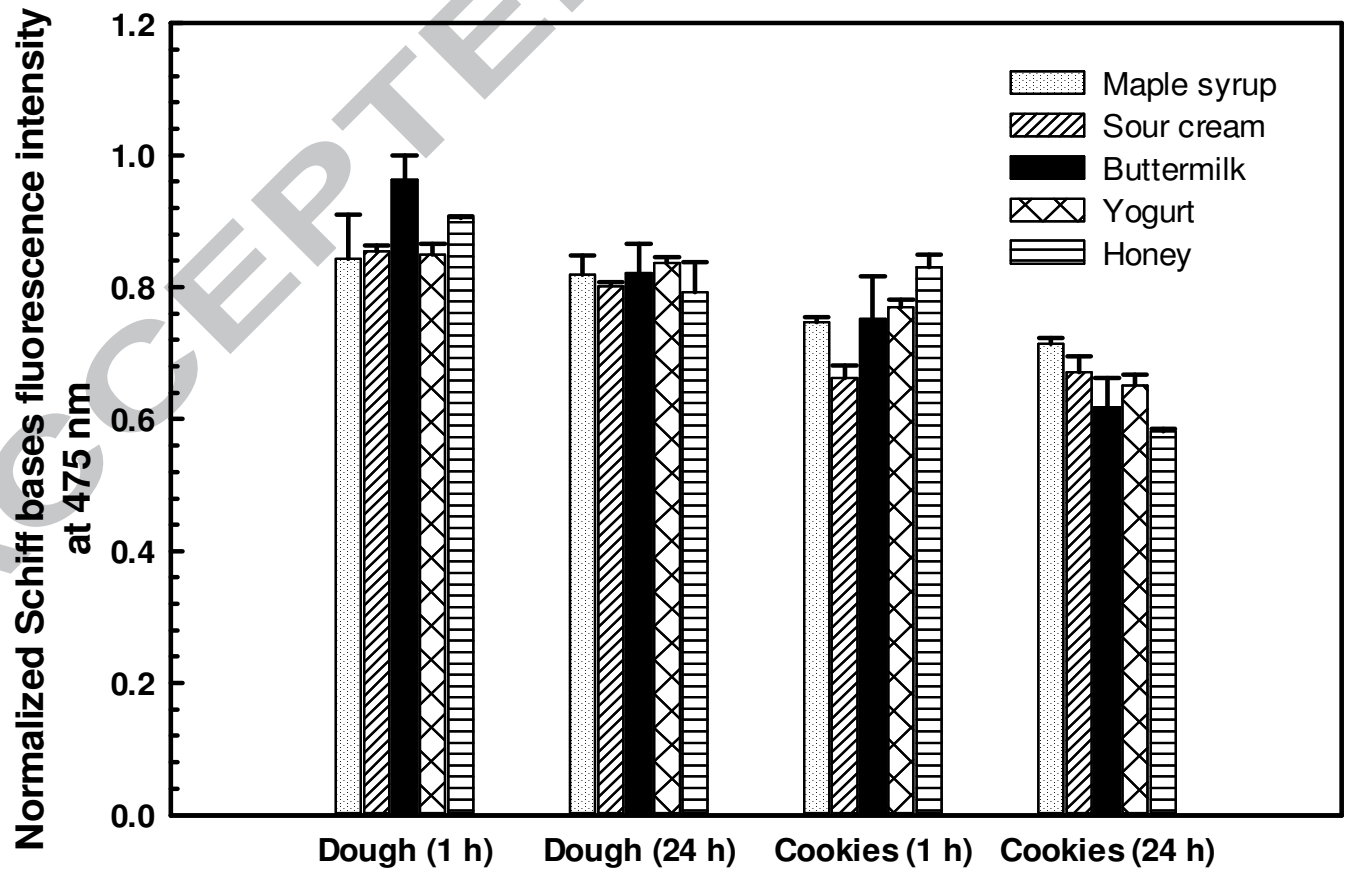

Fig. 4. 


\section{Highlights}

- Use of acidic ingredients decreased greening in cookies made with sunflower butter

- Greening intensity was positively correlated to $\mathrm{pH}(\mathrm{r}=0.77)$

- $\mathrm{pH}$ was negatively correlated with chlorogenic acid $(\mathrm{r}=-0.96)$

- Most green cookies had the most tryptophan quenching

- Greening reaction did not negatively affect antioxidant capacity 